\title{
A tertiary Care Centre Experience with Periampullary and Pancreatic Neoplasm in Pylorus Preserving Pancreatico-Duodenectomy Specimens
}

\author{
Limi Mohandas, Sheela Vasudevan and Kalaranjini KV
}

Department of Pathology, Sree Gokulam Medical College and Research Foundation, Venjaramoodu, Trivandrum, India

\section{ABSTRACT}

Background: Periampullary neoplasms are of pathologic and clinical significance, out of proportion to the small size of the structure. These neoplasms have different long term follow up following resection despite having similar histology.

Methods: A prospective study was done in the department of Pathology, Sree Gokulam Medical College and Research Foundation from Dec 2013 to May 2015 for a period of 18 months. This cross-sectional study included a total of eighteen cases. Study was commenced after approval from institutional ethical committee.

Results: In the present study, females predominated M:F of 1:3.5. The median age for the malignant lesions ranged from 55 yrs to $60 y$ rs and for benign lesions were 30-39years. The most common clinical presentation were neoplastic lesions accounted for $80 \%$ of the total lesions and non neoplastic lesions such as chronic calcific pancreatitis for $20 \%$. Pancreatic adenocarcinoma accounted for most number of lesions. Tumor variables such as perineural invasion and margin status positivitiy were seen in pancreatic carcinomas.

\section{Keywords: Periampullary, Pancreaticoduodenectomy, Perineural Invasion, Lymphnodes Metatases}

\section{Introduction}

Periampullary neoplasms are of pathologic and clinical significance, out of proportion to the small size of the structure. These neoplasms have different long term follow up following resection despite having similar histology. ${ }^{[1]}$

It was Dr William Halstead who performed successful local resection of periampullary neoplasm in a 58year old woman with obstructive jaundice. ${ }^{[2]}$ Dr Allen O Whipple revolutionised and popularised the procedure and which was later named as "Whipples procedure". ${ }^{[3]}$

This procedure proved effective for many patients who had carcinomas arising in the terminal portion of the common bile duct, in the ampulla or periampullary region in the duodenum, as well as for endocrine and other tumors. This procedure has been palliative in patients with infiltrative tumors in reducing the tumor burden. ${ }^{[4,5]}$

The objectives of our study were studying the demographics, clinical presentation, distribution and pathology of various lesions of periampullary region and pancreas in a tertiary care centre like ours.

\section{Materials and Methods}

A prospective study was done in the department of Pathology, Sree Gokulam Medical college and Research
Foundation from Dec 2013 to May 2015 for a period of 18 months. This cross-sectional study included a total of eighteen cases . Preoperative evaluation was standardised and a CT/MRI abdomen were requested in all cases. Percutaneous transhepatic cholangiography, angiography , upper GI endoscopy and CT angiography were optional. Study was commenced after approval from institutional ethical committee.

Inclusion Criteria: Cases with suspected pancreatic/ periampullary cancer that were assumed to be resectable according to preoperative diagnostic work up were included.

Exclusion Criteria: Patients with distant metastasis or locally unresectable tumors, as indicated by preoperative workup and intraoperative findings were excluded.

Pathologic Review: Specimens were dissected according to CAP protocol. Primary Pathology and extent of the disease were determined on gross and microscopic examination. TNM staging was done. Resection margins of the specimens were inked with Indian ink and considered positive if the neoplasm was present at the neck, uncinate processus, CBD, Duodeum/gastric resection, SMA, SMV and retroperitoneal margin.

Statistical Analysis: All variables were entered in excel sheet and analysed by SPSS16. P value was obtained in few variables. 


\section{Results}

In the present study, out of the eighteen cases there were fourteen females $(77.77 \%)$ and four males(2.23\%), with $\mathrm{M}: \mathrm{F}$ of $1: 3.5$. The median age for the malignant lesions ranged from 55 yrs to $60 y r s$ and for benign lesions were 30-39years. The most common clinical presentation were jaundice $(70 \%)$ followed by vague abdominal pain and abdominal discomfort (55\%). Neoplastic lesions accounted for $80 \%$ of the total lesions and non neoplastic lesions such as chronic calcific pancreatitis for $20 \%$ (See Table 1).

Among the neoplastic lesions adenocacinoma of periampullary region accounted for $75 \%$ and others were pancreatic endocrine tumors, IPMN and Mucinous cystadenoma. Pancreatic adenocarcinoma(50\%)was the most common neoplasm arising from the periampullary region, followed by duodenal (33.34\%) and gall bladder(8.34\%). One case was given a broad diagnosis of periampullary carcinoma alone, because its origin was discernible on gross and microscopic examination.

Tumor Characteristics (Table 2) Patients with pancreatic adenocarcinoma (Fig 1) had a mean age of 57yrs and a mean diameter of $39 \mathrm{~mm}$. Majority (5/6) showed moderate differentiation, perineural invasion(4/6) and lymphnode metastases in two out of six cases. These neoplasms accounted maximum for positive resected margins.

Duodenal adenocarcinomas (fig 2) had a mean diameter of $33 \mathrm{~mm}$ and mean age of 57 years similar to pancreatic adenocarcinoma. These tumors also showed moderate differentiation in most cases. They had positive correlation with lymph node metastases. Lymphatic and vascular invasion was seen in a single case and was not statistically significant.

The sample size of gall bladder origin was quite low and their characteristics were not statistically significant.

Among other neoplastic lesions, were two cases of pancreatic endocrine neoplasm (fig 3), one case of mucinous cystadenoma and one case of intraductal papillary mucinous neoplasm (fig 4) which showed characteristic histological features.

Among the non-neoplastic lesions, four cases of pancreatitis were included. However several neoplastic lesions showed adjacent pancreas with chronic calcific pancreatitis owing to a total number of 11 cases of chronic pancreatitis. These patients also had a similar clinical presentation of jaundice and vague abdominal pain as presenting symptom. On histopathology, calcification, fibrosis and islet cell preservation were noticed in all cases.

Table 1: distribution of lesions.

\begin{tabular}{|l|c|}
\hline DISTRIBUTION OF LESIONS & NUMBER OF CASES \\
\hline Pancreatic adeno. Ca & 6 \\
\hline Duodenal adeno. Ca & 2 \\
\hline Pancreatic endocrine & 1 \\
\hline Gall bladder adeno. Ca & 1 \\
\hline Periampullary adenocarcinoma & 1 \\
\hline Intraductal Papillary Mucinous Neoplasm & 1 \\
\hline Mucinous cyst & 2 \\
\hline Chronic calcific pancreatitis & 2 \\
\hline
\end{tabular}

Table 2: Tumour characteristics.

\begin{tabular}{|l|c|c|c|c|c|c|}
\hline TUMOR TYPE & $\begin{array}{c}\text { MEAN } \\
\text { AGE }\end{array}$ & $\begin{array}{c}\text { MEAN } \\
\text { DIA- } \\
\text { METER }\end{array}$ & $\begin{array}{c}\text { DEGREE OF } \\
\text { DIFFERN-TIATION }\end{array}$ & $\begin{array}{c}\text { LYMPHNODE } \\
\text { INVOLVEMENT }\end{array}$ & $\begin{array}{c}\text { PERI- } \\
\text { NEURAL } \\
\text { INVASION }\end{array}$ & $\begin{array}{c}\text { MICRO } \\
\text { VASCULAR } \\
\text { INAVSION }\end{array}$ \\
\hline PAC (6) & 57 & 39 & MODERATE & $2 / 6$ & $4 / 6$ & 0 \\
\hline DAC (4) & 56.88 & 33 & $\begin{array}{c}\text { WELL(1/4) } \\
\text { MODERATE (3/4) }\end{array}$ & $3 / 4$ & $0 / 4$ & $1 / 4$ \\
\hline GB (1) & 59.1 & 54 & WELL & $0 / 1$ & $1 / 1$ & 0 \\
\hline PERIAMPULLARY (1) & 57 & 32 & MODERATE & $1 / 1$ & $0 / 1$ & 0 \\
\hline
\end{tabular}




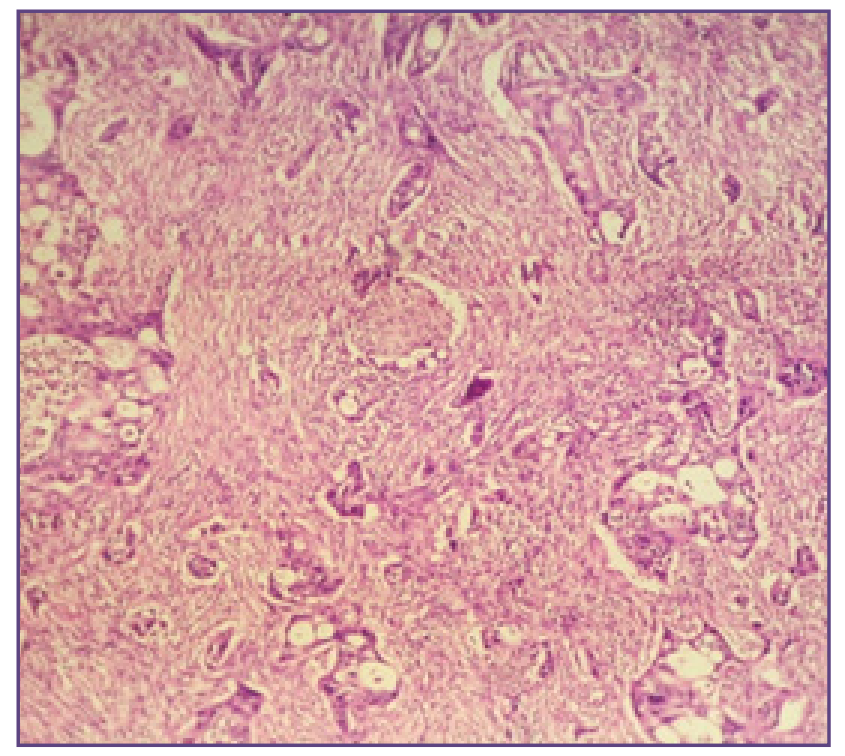

Fig. 1: Pancreatic adenocarcinoma - moderately differentiated (H\&E 40x). small glandular proliferation separated by dense desmoplastic stroma. Perineural invasion by the neoplastic glands are seen.

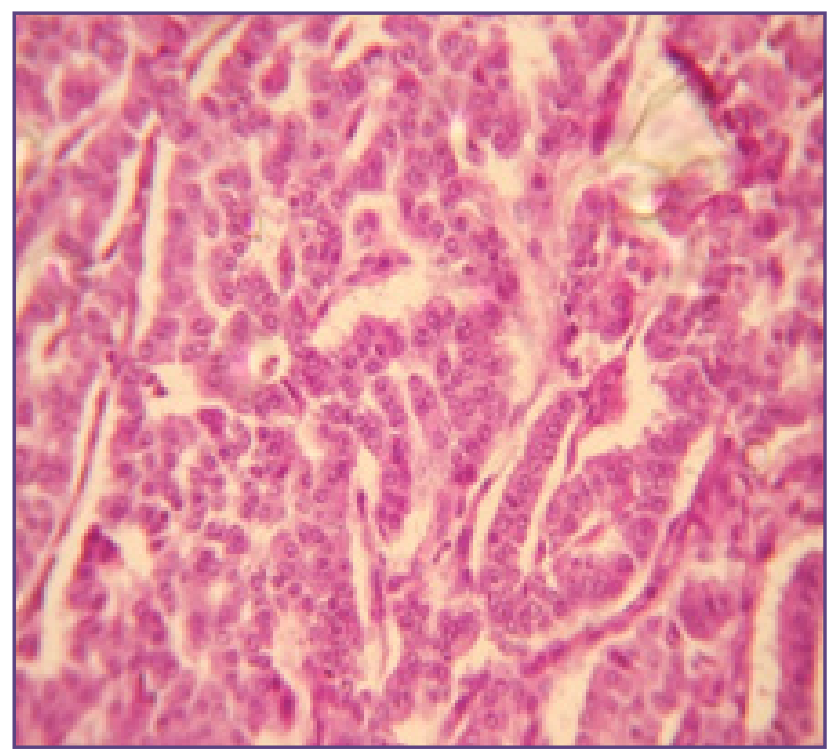

Fig. 3: Pancreatic endocrine neoplasm(H\&E 40x). solid tumor showing nests, insular and trabecular arrangement of cells. The cell showing moderate cytoplasm with enlarged nuclie showing salt and pepper chromatin.

\section{Discussion}

Periampullary and ampullary region has always been a site of interest due to its varied pathology and early symptomatic presentation. ${ }^{[1]}$ The confluence of CBD and main pancreatic duct at the ampulla means that the tumors arising from this location have the ability to obstruct two major organs

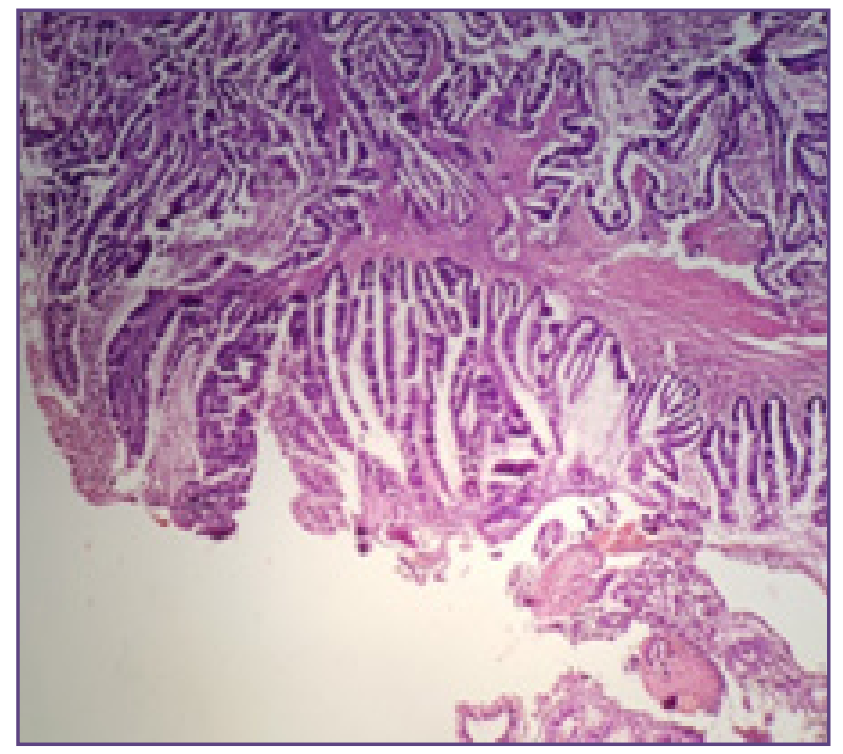

Fig. 2: Duodenal adenocarcinoma (H\&E 40x) Neoplasm arranged in a complex glandular and papillary pattern, lined by tall columnar epithelium with dysplasia(nucleomegaly, pleomorphism, loss of mucin and high $\mathrm{N}: \mathrm{C}$ ratio).

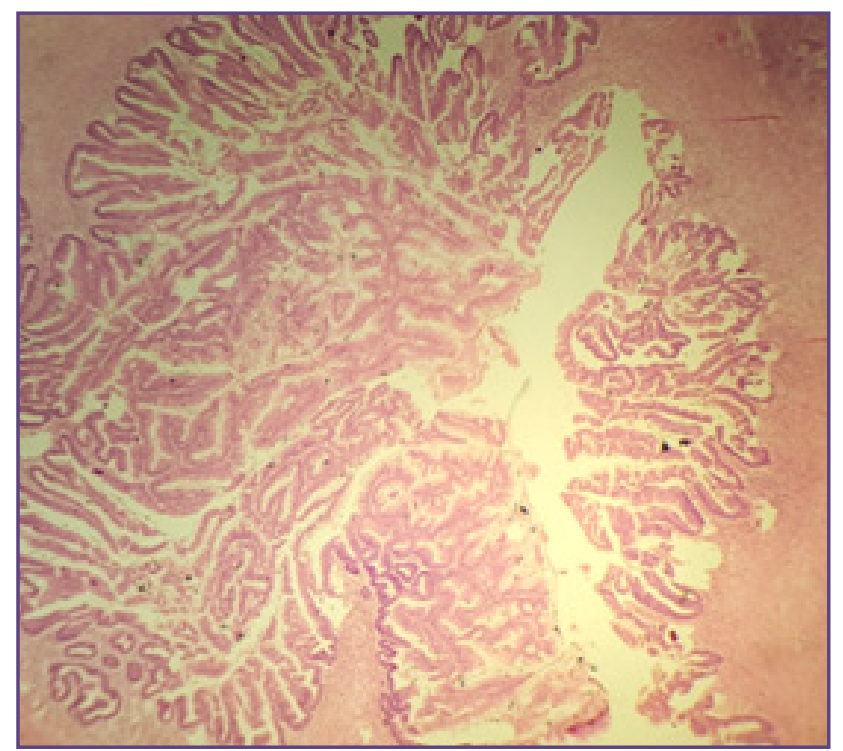

Fig. 4: Intraductal papillary mucinous neoplasm(H\&E 10x). A branch duct showing a neoplasm composed of glands arranged in complex papillary and villous pattern with moderate dysplasia.

and can present as billiary obstruction and pancreatitis. ${ }^{[1]}$ Early symptoms help in early detection of these neoplasms and hence appropriate management can be rendered to the patient. Therefore we studied the clinical and pathological features which help in ascertaining the type and origin of the tumors and variables associated with it. ${ }^{[5]}$ 
In our study series of periampullary and pancreatic pathology, the demography variable such as mean age(57yrs) were concordant with Yeo et al ${ }^{[6]}$,Cameron et ${ }^{a l[7]}$ and Tran et al. ${ }^{[10]}$ However our study showed a female predominance unlike other studies which showed male predominance. . $^{[6,7,8,9,10]}$

Among the neoplastic lesions, maximum lesions were noticed in pancreas which was comparable to Yeo et al ${ }^{6,9}$ and Cameron $\mathrm{Et} \mathrm{al}^{7,2}$. Pancreatic adenocarcinomas are the most common pathology presenting as mass in periampullary region. In the present study these adenocarcinomas had a mean diameter of $39 \mathrm{~mm}$ which was comparable to Yeo et al series. ${ }^{[6,9]}$ On gross examination these neoplasms was seen involving head and body of pancreas, firm to hard in consistency and grey white in appearance. Microscopic examination revealed proliferation of small glands separated by desmoplastic stroma, with cytologically deceptive benign features. Few subtypes of pancreatic adenocarcinoma was seen, among them colloid carcinoma (fig 3a\&3b) being one. These neoplasms were distinctive with their gross and microscopy features. They had an average diameter of $54 \mathrm{~mm}$, which was comparable to Adsay NVet al. ${ }^{[11]}$ Gross examination revealed soft to firm mass with gelatinous glistening like appearance, similarly microscopy showed abundant pools of mucin with sparse glands. In a study done by Adsay et al ${ }^{[12]}$ these neoplasms were composed of well-defined pools of mucin with sparse malignant cells in various patterns of distribution. Immunohistochemical and histochemical mucin stains suggested luminalization of the basal aspects of the cells.

Perineural invasion is often considered as a prognostic factors and a characteristic histological feature in pancreatic adenocarcinoma. ${ }^{[12]}$ This is attributed to the acute neurotropism of pancreatic cells along with innervation of the gland. Some authors have demonstrated that perineural invasion is the first step before nodal invasion. ${ }^{[12]}$ The characteristic perineural invasion was lacking in colloid carcinoma this was comparable with Ake Andre Sandberg et al. ${ }^{[13]}$

In the present study several other pathologies were seen, which included pancreatic endocrine neoplasm(2), and other cystic neoplasms i.e., mucinous cystadenoma and intraductal papillary mucinous neoplasm.

Pancreatic endocrine neoplasm are uncommon tumors with an annual incidence $<1 / 100000$ persons per year.

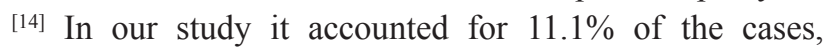

these neoplasms were encapsulated with grey white appearance and areas of haemorrhage. One of the case showed predominant vascular proliferation with areas of haemorrhage. ${ }^{[15]}$ The usual histologic appearance is that of a solid nesting architecture; the tumor cells are round to ovoid with eosinophilic, slightly granular cytoplasm and dispersed nuclear chromatin resembling 'salt and pepper.' Immunohistochemistry plays a significant role in the diagnosis of endocrine neoplasms. They are synaptophysin and chromogranin positive, with synatpophysin being a more specific marker. ${ }^{[16]}$

Cystic neoplasm of pancreas include an exhaustive list of conditions. However very often encountered and chief lesions include serous cystic neoplasm, mucinous cystic neoplasms, intraductal papillary mucinous neoplasm and solid pseudopapillary neoplasm. ${ }^{[15]}$ In our study we came across IPMN and Mucinous cystic neoplasm.

Intraductal papillary mucinous neoplasms of the pancreas (IPMN) display differing degrees of dysplasia and vary in terms of their malignant potential. ${ }^{[17]}$ IPMN are noninvasive precursor lesions reflective of an underlying field defect and genetic instability, placing the entire gland at increased risk for cancer development. ${ }^{[18]}$ A single case of intraductal mucinous neoplasm was obtained in this study. In the present study it presented as cystic neoplasm involving the head of pancreas, involving the branch duct. On microscopy it had histological features of intestinal type with moderate degree of dysplasia. According to the study done by Julie. N. Leal IPMN was most common in head of pancreas, showing involvement of branch duct however on histology gastric type of mucinous epithelium was more common as opposed to our study. ${ }^{[19]}$

Mucinous cystic neoplasm of pancreas are often seen in younger age with female predilection. Most often found in the body and tail of pancreas. They show a standout characteristic ovarian stroma on microscopy and these stromal cells show oestrogen and progesterone sensitivity. [20] Very often IPMN forms the differential diagnosis of mucinous cystic neoplasms. Mucinous neoplasm can be differentiated by its ovarian stroma and lack of characteristic duct involvement. ${ }^{[21]}$

Duodenal adenocarcinoma was the second common neoplasm involving periampullary region, which was least common in other series. Duodenal adenocarcinoma often presents as a polypoidal mass (fig involving in and around the ampulla. ${ }^{[15]}$ These adenocarcinomas were composed 
of proliferated glands in complex papillary and villous pattern with areas of necrosis and calcification. Duodenal adenocarcinomas showed maximum number of node positivity which was comparable with Yeo et al..$^{[6,9]}$

Majority of the adenocarcinomas (pancreatic, duodenal and Gallbladder) showed moderate differentiation which according to Yeo et ${ }^{a[6,9]}$ and Cameron et al ${ }^{[7,2]}$ were features of favourable long term prognosis. Few features such as node positivity and margin positivity, considered as poor prognostic variables according to $\mathrm{Yeo}$ et al ${ }^{[6,9]}$ were seen in our series in duodenal and pancreatic adenocarcinomas respectively.

Non neoplastic lesions of pancreas included only cases of pancreatitis. 4/6 cases of pancreatic adenocarcinoma showed chronic calcific pancreatitis. Several data exist to indicate association between chronic pancreatitis and pancreatic adenocarcinoma. ${ }^{[2]}$ Two theories has been proposed regarding this association, one being carcinoma arising from chronic pancreatitis ${ }^{[23]}$ and the other is chronic pancreatitis developing secondary to carcinoma The second theory can attributed to obstruction of the ducts by tumours leading to chronic pancreatitis. ${ }^{[20]}$ Majority of the cases showed fibrosis, calcification and islet preservation as the characteristic features. ${ }^{[21]}$

\section{Conclusion}

In our study we have concluded that there is a change in gender predilection and possible emergence of duodenal adenocarcinomas in future era. The association of chronic pancreatitis and pancreatic adenocarcinoma still debatable. Our study also showed several prognostic variables similar to other studies with no significant change in the recent past.

\section{References}

1. Klimstra D, Volkan AN. Tumors of pancreas and ampulla of vater. Odze Robert D, and. Goldblum John R, Surgical Pathology of the GI Tract, Liver, Biliary Tract and Pancreas, 3rd Edition Elsevier. 2009: 909-60

2. Cameron JL, Riall TS, Coleman J, Belcher KA. One Thousand Consecutive Pancreaticoduodenectomies. Annals of Surgery. 2006;244(1):10-15.

3. Whipple AO. A reminiscence: pancreaticoduodenectomy. Rev Surg.1963;20:221-25

4. Jones BA, Langer B, Taylor BR, Girotti M. Periampullary tumors which ones should be resected? Am J Surg 1985; 149:46-51.
5. Grace PA, Pitt HA, Tompkins RK, et al. Decreased morbidity and mortality after pancreaticoduodenectomy. Am J Surg 1986; 151:141-149.

6. MH van Roest, A.S. Gouw, S, H. Annette Results of pancreaticoduodenectomy in patients with periampullary adenocarcinoma: perineural growth more important prognostic factor than tumor localization.Ann Surg. 2008 Jul; 248(1):97-103

7. Yeo CJ, Sohn TA, Cameron JL, Hruban RH, Lillemoe KD, Pitt HA. Periampullary adenocarcinoma: analysis of 5-year survivors. Annals of Surgery. 1998; 227(6):821-831.

8. Cameron JL, Pitt HA, Yeo CJ, Lillemoe KD, Kaufman HS, Coleman J. One hundred and forty-five consecutive pancreaticoduodenectomies without mortality. Annals of Surgery. 1993; 217(5):430-438.

9. Yeo, C. J., Cameron, J. L., Sohn, T. A., Lillemoe, K. D., Pitt, H. A., Talamini, et al. Six hundred fifty consecutive pancreaticoduodenectomies in the 1990s: pathology, complications, and outcomes. Annals of Surgery. 1997;226(3):248-260

10. Tran KTC, Smeenk HG, van Eijck CHJ, et al. Pylorus Preserving Pancreaticoduodenectomy Versus Standard Whipple Procedure: A Prospective, Randomized, Multicenter Analysis of 170 Patients With Pancreatic and Periampullary Tumors. Annals of Surgery. 2004;240(5):738-745. .

11. Adsay NV, Pierson C, Sarkar F et al. Colloid (mucinous noncystic) carcinoma of the pancreas. Am J Surg Pathol. 2001 Jan;25(1):26-42.

12. Fouquet, T., Germain, A., Brunaud, L. Bresler L, Ayav A. Is perineural invasion more accurate than other factors to predict early recurrence after pancreatoduodenectomy for pancreatic head adenocarcinoma? World J Surg (2014) 38: 2132

13. Andrén-Sandberg Å. Prognostic Factors in Pancreatic Cancer. North American Journal of Medical Sciences. 2012;4(1):9-12.

14. Verbeke CS . Endocrine tumours of the pancreas. Histopathology 2010, 56, 669-682.

15. Kloppel G, Heitz U P. Tumors of the endocrine Pancreas. Fletcher Christopher D. M. Diagnostic Histopathology of Tumors. 3rd edition volume 2 Elsevier.2007: 1124-34

16. Asa Sylvia L. Pancreatic endocrine tumors. Modern Pathology (2011) 24, S66-S77

17. D'Angelica M, Brennan MF, Suriawinata AA, Klimstra D, Conlon KC., Intraductal papillary mucinous neoplasms of the pancreas: an analysis of clinicopathologic features and outcome. Ann Surg, 2004. 239(3): p. 400-8.

eISSN: 2349-6983; pISSN: 2394-6466 
18. Hruban RH, Takaori K, Canto M, Fishman EK, Campbell K, Brune K,et al., Clinical importance of precursor lesions in the pancreas. J Hepatobiliary Pancreat Surg, 2007. 14(3): p. 255-63.

19. Julie N. Leal. T. Peter Kingham. Michael I. D’Angelica. Intraductal Papillary Mucinous Neoplasms and the Risk of Diabetes Mellitus in Patients Undergoing Resection Versus Observation. J Gastrointest Surg (2015) 19:1974-1981

20. uan R. Pancreas and ampullary region. Rosai and Ackerman's Surgical pathology. Tenth edition volume 2 Elsevier 2012. 1021-22
21. Cunningham SC, Hruban RH, Schulick RD. Differentiating intraductal papillary mucinous neoplasms from other pancreatic cystic lesions. World Journal of Gastrointestinal Surgery. 2010;2(10):331-336.

22. Dhar P, Kalghatgi S, Saraf V. Pancreatic Cancer in Chronic Pancreatitis. Indian J Surg Oncol 2015; 6(1):57-62

23. Buckminster F, Yuko S, Chen A, BS,Ekong Uffort, et al. Inflammatory Mechanisms Contributing to Pancreatic Cancer Development Ann Surg 2004;239: 763-771

*Corresponding author:

Dr. Limi Mohandas, Department of Pathology,S ree Gokulam Medical College and Research Foundation Venjaramoodu, Trivandrum 695607,India, Phone: +91 8592929206

Email: limi.mohandas@gmail.com

Date of Submission : 04.12.2016

Date of Acceptance : 28.04.2017

Financial or other Competing Interests: None.

Date of Publication : 31.08.2017 